\title{
Influência das características socio- econômicas de agricultores familiares na adoção de sistemas agroflorestais
}

\section{AUTORES: \\ Gisele do Socorro dos Santos Pompeu ${ }^{1}$ \\ Leonilde dos Santos $\operatorname{Ros}^{2}$ \\ Silvio Levy Franco Araújo $^{3}$ \\ Andrea Braga Boaventura Araújo ${ }^{2}$ Erycéle de Lima Silveira ${ }^{4}$ \\ ${ }^{1}$ Faculdade de Engenharia Flores- tal, Universidade Federal do Pará, 60.371-030, Altamira, PA, Brasil. \\ 2 Universidade Federal Rural da Amazônia, 66.077-901, Belém, PA, Brasil. \\ ${ }^{3}$ Embrapa/ACN, 69.301-970, Boa Vista, RR, Brasil. \\ ${ }^{4}$ Secretaria de Estado de Meio Ambiente, 66.095-770, Belém, PA, Brasil.}

Recebido: 13/01/2011

Aprovado: 09/05/2011

AUTOR CORRESPONDENTE:

Leonilde dos Santos Rosa

E-mail:leonile.rosa@ufra.edu.br

PALAVRAS-CHAVE:

Microrregião bragantina

Amazônia

Agroecossistema

KEY WORDS:

Microregion bragantina

Amazon

Agroecosystem

\section{Influence of socioeconomic characteristics of small farmers on the adoption of agroforestry systems}

RESUMO: Os sistemas agroflorestais (SAFs) surgem como uma alternativa à agricultura de derruba e queima praticada na Amazônia. Assim, o objetivo do estudo foi analisar a influência das características socioeconômicas de agricultores familiares na adoção de SAFs comerciais. A pesquisa foi desenvolvida em Bragança, no Estado do Pará. Na coleta de dados foram empregadas entrevista estruturada e observação direta, ambas são ferramentas do Diagnóstico Rural Rápido. Os dados foram analisados pela estatística descritiva e análise de correlação linear. Foram identificadas 53 famílias de agricultores com SAFs, em 19 comunidades rurais. As características socioeconômicas identificadas neste estudo, como a procedência dos agricultores; organização local; idade; nível de escolaridade; posse da terra; tamanho do lote e do SAF; mão de obra familiar e geração de renda, influenciaram a adoção de sistemas agroflorestais comerciais em Bragança. A mão de obra familiar representa a maior expressão nos trabalhos desenvolvidos na unidade de produção. O homem desenvolve as principais atividades produtivas e é o principal responsável pela adoção destes sistemas. Os SAFs, em geral, são importantes para a economia dos agricultores familiares. Contudo, algumas políticas públicas são necessárias para que estes sistemas se tornem sustentáveis, do ponto de vista socioeconômico. Elas devem ampliar as áreas dos SAFs comerciais, garantir assistência técnica eficiente aos agricultores, adequar os produtos gerados ao mercado consumidor, capacitar os agricultores em relação ao manejo dos SAFs, para aumentar a renda gerada por estes sistemas, e finalmente empoderar os produtores rurais sobre os projetos de financiamento.

ABSTRACT: Agroforestry systems (AFSs) have emerged as an alternative to the slash and burn agriculture practiced in the Amazon region. This study therefore aims to analyze the influence of the socioeconomic characteristics of farmers on the adoption of agroforestry systems. The study was carried out in Bragança ( $01^{\circ} 03$ '15' S and 46 $\left.{ }^{\circ} 46^{\prime} 10^{\prime \prime} \mathrm{W}\right)$, in the Brazilian State of Pará. Data was collected by way of structured interviews and direct observation, both of which are Rapid Rural Evaluation tools. The data were analyzed using descriptive statistics and linear correlation. Fifty-three smallholders with AFSs were identified in 19 rural communities. The socioeconomic characteristics identified in this study, such as the origin of the farmers, social organization, age, level of education, land tenure, and lot- and AFS-size, as well as labor force and income generation, influenced the adoption of commercial agroforestry systems in Bragança. The family is the most common source of labor in family production units. The man carries out the main productive activities related to commercial AFSs, and is responsible for the adoption of these systems. The AFSs, in general, are important for the economy of small farmers in Bragança. However, public policies are needed for these systems to become socioeconomically sustainable, including: expanding the areas of commercial AFSs; ensuring efficient technical assistance is provided for farmers; adapting the products to the consumer market, enabling farmers to manage agroforestry systems, increasing the income generated by these systems; and finally empowering the farmers to establish funding projects. 


\section{Introdução}

Na Amazônia, a prática da agricultura de corte e queima associada à expansão da fronteira agrícola acarreta problemas de ordem social, econômica e ambiental. Esta realidade tem impulsionado estudos no sentido de propor uma reorientação dos sistemas de produção empregados no campo pelos agricultores familiares, de modo a disponibilizar alternativas mais sustentáveis para a produção de alimentos.

Neste contexto, os sistemas agroflorestais (SAFs) surgem como uma alternativa à agricultura itinerante praticada na Amazônia (DUBOIS, 1996). De acordo com este autor, os SAFs são sistemas de uso da terra nos quais árvores ou arbustos são utilizados em associação com cultivos agrícolas e/ou com animais, numa mesma área, simultaneamente ou em sequência temporal.

Apesar de ocuparem uma pequena parcela das terras cultivadas na Amazônia, os SAFs podem ser uma opção para gerar renda em áreas relativamente pequenas de agricultores familiares, na Amazônia (ROSA et al., 2009), para diminuir a pressão sobre a floresta primária e secundária, além de manterem a fertilidade do solo pela deposição da matéria orgânica proveniente das espécies vegetais e animais (DUBOIS, 1996) e se aproximarem da estrutura e dinâmica da vegetação natural (MAIA; CELESTINO FILHO; SALGADO, 2003).

Não obstante, os registros, na literatura, que tratam de experiências de SAFs na Região Amazônica ainda são escassos, sobretudo em relação às características socioeconômicas que afetam a adoção de SAFs no universo da agricultura familiar.

De acordo com Franke, Lunz e Amaral (1998), é no estudo socioeconômico e do meio físico que se assenta o planejamento do uso da terra, um instrumento que permite conhecer as condições demográficas, os sistemas de produção, o manejo e uso da terra, os problemas, os anseios e as dificuldades do agricultor.

O objetivo do estudo foi analisar a influência das características socioeconômicas de agricultores familiares na adoção de sistemas agroflorestais comerciais.

\section{Material e Métodos}

A pesquisa foi desenvolvida em Bragança $\left(01^{\circ}\right.$ 03 ' 15" S e 46 46' 10" W), na microrregião Bragantina, no Estado do Pará. De acordo com a classificação de Köopen, Bragança apresenta clima do tipo Ami, com precipitação pluviométrica média anual de $2390 \mathrm{~mm}$, temperatura de $25,7^{\circ} \mathrm{C}$ e umidade relativa do ar de $83,2 \%$. A cobertura vegetal atual nas áreas de terra firme é composta por florestas secundárias. Predominam neste município os seguintes solos: Argissolo e Latossolo Amarelo (ESTATÍSTICAS..., 2007).

$\mathrm{Na}$ coleta de dados foram empregadas entrevista estruturada e observação direta, ambas ferramentas do Diagnóstico Rural Rápido-DRR (CHAMBERS, 1987). As entrevistas foram realizadas com agricultores locais e com informantes "chaves", representantes do Sindicato de Trabalhadores Rurais de Bragança, de associações comunitárias e de órgãos governamentais que atuam na agricultura familiar. O roteiro da entrevista abordou os seguintes aspectos: origem, escolaridade, idade, sexo, força de trabalho familiar, tamanho do lote e do SAF, geração de renda, questões organizacionais e os demais sistemas de uso da terra praticados pelos agricultores locais.

A utilização das ferramentas do DRR e a participação de vários atores sociais favoreceram a triangulação, aumentando a segurança dos dados coletados. Com o auxílio do programa Bio Estat 4.0, os dados foram analisados pela estatística descritiva. O grau de associação entre o tamanho do lote e o tamanho do SAF foi analisado por correlação linear de Pearson.

\section{Resultados e Discussão}

Foram identificadas 53 famílias de agricultores familiares com 62 experiências de sistemas agroflorestais comerciais multiestratificados, em 19 comunidades de Bragança. Predominavam nestes SAFs espécies permanentes e temporárias, sobretudo frutíferas e agrícolas. As associações de espécies mais frequentes nos SAFs foram: a) Citrus sinensis (L) Osb. (laranjeira) e Vigna sp (feijão); b) Cocus nucifera L. (coqueiro) e Vigna sp; c) C. nucifera e $C$. sinensis; d) C. nucifera, Vigna sp e C. sinensis; e) C. sinensis, Vigna sp; e Manihot esculenta Crantz (mandioca); f) C. nucifera, C. sinensis e Piper nigrum Vell (pimenta-do-reino).

A preferência dos agricultores familiares por espécies frutíferas e culturas de ciclo curto de valor comercial foi observada em outros estudos realizados na microrregião Bragantina (VIEIRA et al., 2007; POMPEU et al., 2009). Esta preferência pode estar relacionada a questões econômicas e socioculturais. Pesquisas desenvolvidas por Rosa et al. (2009) so- 
bre a adoção de SAFs comerciais na microrregião Bragantina revelaram que os agricultores nortistas preferem espécies frutíferas e culturas de ciclo curto comerciais que fazem parte da dieta local.

Em Bragança, foi constatado que 96,2\% dos agricultores com SAFs eram provenientes da Região Norte e 3,8\% da Região Nordeste do Brasil. Os agricultores nortistas eram oriundos do Estado do Pará, sendo que 82,4\% nasceram em Bragança, porém muitos eram descendentes de nordestinos; o que explica a preferência por estas espécies.

Foi observado que $68 \%$ dos agricultores que adotaram SAFs encontravam-se na faixa etária de 29 a 58 anos de idade. O agricultor com idade entre 59 e 89 anos correspondeu a $24,6 \%$ do total. Apenas $7,6 \%$ dos agricultores tinham idade inferior a 29 anos. A idade média dos agricultores familiares, em Bragança, foi de 50 anos. A idade mais frequente foi 48 anos (Tabela 1). Nota-se que ocorreu uma grande amplitude em relação à idade mínima e máxima.

Tabela 1. Análise descritiva referente à idade dos agricultores familiares que adotaram sistemas agroflorestais no município de Bragança, Pará. n=53

\begin{tabular}{lc}
\hline Medidas Estatísticas & Idade (anos) \\
\hline Média & 50 \\
Mediana & 52 \\
Moda & 48 \\
Desvio padrão & 11,3 \\
Mínimo & 20 \\
Máximo & 73 \\
\hline
\end{tabular}

Os dados obtidos em Bragança denotam que a maioria dos agricultores com SAFs comerciais está em plena capacidade produtiva de trabalho. Outro aspecto a ser ressaltado é a baixa frequência de resposta dos agricultores idosos à adoção de SAFs. Para Rosa et al. (2009) e Vieira et al. (2007), a baixa adoção do agricultor idoso aos SAFs deve-se ao fato dele privilegiar atividades que exigem menor esforço físico e apresentar maior resistência à introdução de novas tecnologias. Este tipo de resistência também foi observado em Moju, Pará (ROSA, 2002) e Santo Antônio do Tauá-Pará (PEREIRA, 2004). Cabe mencionar que, em Bragança, muitos agricultores com idade acima de 60 anos são aposentados ou pensionistas, não sendo os SAFs, portanto, a única fonte de renda destes agricultores, o que também explicaria a baixa adoção de SAFs nesta faixa etária.

O nível de escolaridade dos agricultores familiares foi baixo, uma vez que $8 \%$ dos agricultores não eram alfabetizados, aproximadamente $81 \%$ atingiram o ensino fundamental e apenas 11,3\% alcançaram o ensino médio, porém, nem todos conseguiram concluí-lo (Figura 1). Estes dados apontam para um déficit educacional a ser superado entre os agricultores que adotaram SAFs, em Bragança.

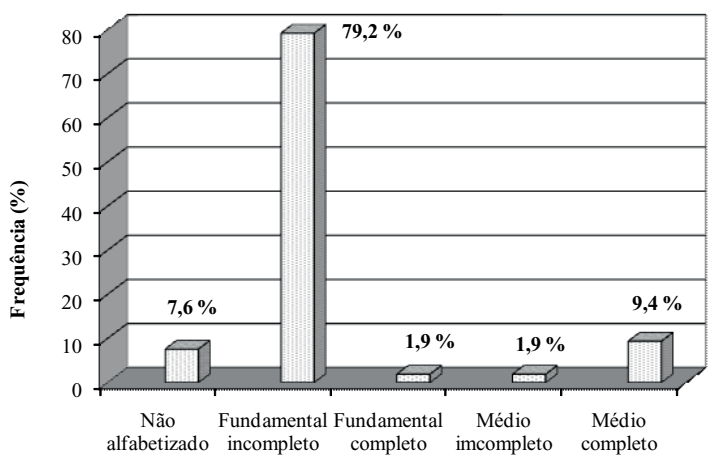

Figura 1. Nível de escolaridade dos agricultores familiares que implantaram SAFs em Bragança, Pará.

O baixo percentual de agricultores com o ensino médio pode ter sido ocasionado pelo fato das escolas existentes nas comunidades oferecerem mais vagas para o ensino fundamental. A carência de escolas de ensino médio no meio rural também foi constatada por Vieira et al. (2007), em Igarapé Açu, Estado do Pará.

Muito embora o nível de escolaridade apresente relação direta e positiva com a adoção de SAFs (PEREIRA, 2004; ROSA et al., 2009) e com a capacidade de acesso à informação e ao crédito para o estabelecimento de SAFs (FRANZEL et al., 2002), em Bragança a escolaridade não se tornou uma barreira para a adoção destes sistemas, visto que agricultores não alfabetizados ou com ensino médio completo estabeleceram sistemas agroflorestais, o que também foi observado por Vieira et al. (2007), em SAFs adotados por agricultores familiares de Igarapé Açu, e Rosa et al. (2009), em seus estudos sobre adoção de SAFs na microrregião Bragantina.

Foi constatado que, dentre as 19 comunidades que desenvolvem experiências com sistemas agroflorestais, apenas sete possuem alguma forma de organização local. Esta pesquisa revelou, ainda, que $92 \%$ dos agricultores estão associados às organizações comunitárias formais existentes em Bragança como, por exemplo, o Sindicato de Trabalhadores Rurais. O percentual restante (8\%) não participa de nenhuma organização comunitária formal. Estes dados apontam para a importância das organizações comunitárias para a adoção de SAF, em Bragança. Para Vieira et al. (2007) e Rosa et al. (2009), a or- 
ganização social dos agricultores tem relação direta com a adoção de SAFs na microrregião Bragantina.

Apesar disso, estudos realizados sobre o papel das organizações comunitárias em Bragança (LUDOVINO, 2002) mostram que, mesmo existindo um grande número de associações comunitárias neste município, o objetivo da criação foi exclusivamente para obter crédito do programa FNO. Para o autor, estas associações nunca desempenharam de fato as funções preconizadas para este tipo de organização.

Em se tratando da força de trabalho familiar, observou-se que ocorreu uma grande amplitude em relação ao número de pessoas e à força de trabalho disponível na família, cuja média foi de 4,5 pessoas (Tabela 2).

Tabela 2. Número de pessoas e força de trabalho disponível nas famílias de agricultores que adotaram SAFs em Bragança, Pará. n=53

\begin{tabular}{lcccc}
\hline \multicolumn{1}{c}{ Variável } & Mínimo & Médio & Máximo & Frequência (\%) \\
\hline Número de pessoas na família & 1 & 4,2 & 18 & - \\
Força de trabalho disponível na família & 1 & 4,5 & 16 & - \\
Mão de obra familiar & - & - & - & 60,4 \\
Mão de obra familiar mais terceiros & - & - & - & 39,6 \\
\hline
\end{tabular}

A mão de obra exclusivamente familiar correspondeu a aproximadamente $60 \%$, representando a maior expressão nos trabalhos desenvolvidos na unidade de produção. Por sua vez, a mão de obra externa, contratada especialmente nos períodos de preparo da terra e colheita, evidenciou que os SAFs podem promover a geração de emprego, mesmo que temporário.

Os resultados sobre a mão de obra obtidos em Bragança assemelham-se aos observados em comunidades do Moju-PA (ROSA, 2002). Esta autora relatara, em seu trabalho, que a mão de obra utilizada nos estabelecimentos agrícolas estudados foi, em sua maioria, de procedência familiar.

Dentre as 53 famílias que adotaram SAFs, em Bragança, constatou-se que o homem é quem exerce o papel de chefe de família. A mulher desempenha esta função quando é viúva, solteira ou separada. Estes dados indicam que grande parte da tomada de decisão sobre a adoção dos SAFs e demais atividades executadas no lote cabe ao homem. A efetiva participação do homem na adoção destes sistemas deve-se, provavelmente, à sua maior visibilidade e acesso aos recursos em decorrência do modelo patriarcal predominante no meio rural.

As atividades em que todos os membros da família tinham maior participação foram: plantio, capina, colheita e produção de farinha. Quando se analisa a divisão das atividades dos membros das famílias dos agricultores de Bragança, observa-se que, apesar da mulher não ser a principal responsável pelas decisões nos SAFs, ela exerce papel importante nas atividades de plantio, colheita e produção de farinha de mandioca (Tabela 3).

A produção de farinha, segundo Rosa (2002), é uma atividade importante, tanto do ponto de vista da produção quanto da reprodução social. Nas palavras desta autora, esta atividade "merece destaque especial não somente pelo aspecto econômico, mas também pelo lado social, visto que ela aumenta as relações sociais entre os membros das famílias (esposa, marido e filhos e parentes próximos) e entre as famílias locais".

Tabela 3. Divisão do trabalho em áreas de agricultores familiares que adotaram SAFs no Município de Bragança, Pará. $\mathrm{n}=53$

\begin{tabular}{lrrrrrrr}
\hline \multirow{2}{*}{ Atividades } & \multicolumn{7}{c}{ Elementos da família (\%) } \\
\cline { 2 - 8 } & Pai & Mãe & Mãe/Filho & Pai/Filho & Mãe/Pai & Filho & Todos \\
\hline Preparo da área & 3,8 & - & - & 81,1 & 1,6 & 7,9 & 5,7 \\
Plantio & 3,8 & 0,8 & 1,9 & 32,1 & 1,9 & 18,9 & 40,7 \\
Capina & 5,7 & - & 1,9 & 45,3 & 1,89 & - & 45,3 \\
Poda & 4,3 & - & 1,9 & 81,1 & 1,9 & 3,8 & 7,1 \\
Colheita & 3,8 & 1,00 & 1,9 & 9,4 & 1,9 & 3,8 & 78,3 \\
Comercialização & 66,0 & 0,8 & 5,0 & 16,8 & 7,6 & 1,9 & 1,9 \\
Trabalho doméstico & 7,3 & 71,6 & 13,9 & - & 1,9 & 1,1 & 4,2 \\
Produção de farinha & 11,2 & 7,2 & 2,4 & 10,3 & 7,3 & 1,4 & 60,2 \\
\hline
\end{tabular}

A mão de obra feminina é muito importante na propriedade rural, pois, além das atividades produtivas nos SAFs, 71,6\% realizam trabalhos domésticos e algumas realizam atividades externas, como lecionar em escolas da comunidade. A pluriatividade na agricultura familiar é um fenômeno comumente observado no universo da agricultura familiar, na Amazônia. De acordo com Rosa (2002), "este fenômeno está inteiramente relacionado com a disponibilidade de mão de obra familiar e esta, por sua vez, com o calendário agrícola e, por conseguinte, com a sazonalidade".

Em Bragança, cerca de 7\% dos homens realizam, sozinhos, o trabalho doméstico (Tabela 3). Isto ocorre nos casos em que o homem é solteiro, viúvo ou separado. O homem (pai e filho) tem maior destaque nas atividades de preparo da área, capina, comercialização e poda das espécies dos SAFs (Tabela 3). A participação da mulher na comercialização dos produtos se restringiu a pouco menos de $1 \%$. Segundo Rosa et al. (2007), em geral isto 
ocorre porque a mulher detém poucas informações sobre a cadeia produtiva e o mercado dos produtos gerados na agricultura, além de ter pouco conhecimento sobre gestão de propriedades para conduzir o empreendimento familiar. Aliado a isso, está o fato do homem associar esta atividade como prática masculina.

Sobre o trabalho executado pelo sexo masculino nos SAFs, Siliprandi (2000), Vieira et al. (2008) e Vieira et al. (2009) observaram, em seus estudos, que os homens são responsáveis por atividades que exigem maior esforço físico, tais como derrubada e queima da vegetação. As mulheres costumam auxiliar nas atividades menos pesadas, como plantio e colheita, características que também foram observadas em Bragança.

O caráter "pesado" ou "leve" das atividades é destacado por Brumer (2004) como algo relativo e culturalmente determinado, uma vez que, na esfera de suas atividades, a mulher executa trabalhos "leves" e "pesados", como colheita dos produtos agrícolas e obter água em lugares distantes da casa. A autora destaca dois aspectos que podem explicar a divisão de trabalho entre homens e mulheres rurais: a unidade familiar reúne esforços dos membros da família para benefício mútuo e a vivência em uma sociedade patriarcal, em que se atribui ao homem a responsabilidade pelo provimento da família e administração da propriedade.

Em relação à situação fundiária dos lotes, foi constatado que quase $93 \%$ dos agricultores possuem o título definitivo da terra, e o percentual restante encontra-se na situação de ocupante. Nenhum agricultor possui lote arrendado ou trabalha sob parceria. Estes resultados podem ser explicados pelo fato do município estar localizado em uma antiga fronteira agrícola em que a maioria dos agricultores já recebeu seus títulos definitivos dos lotes. Estes dados apontam para o fato de que, em Bragança, a posse da terra influenciou na adoção de SAFs. No entanto, como 7\% dos agricultores com SAFs não possuem o título definitivo da terra, pode-se inferir que a posse da terra não foi um fator determinante para a adoção destes sistemas em Bragança.

Estudos realizados na microrregião Bragantina (VIEIRA et al., 2007; ROSA et al., 2009) mostraram que a posse do lote não é um fator limitante para a adoção de SAFs nesta microrregião. Vale mencionar que pesquisas recentes desenvolvidas em Bragança mostram que a carência de assistência técnica, aliada à falta de equipamentos, são as duas maiores barreiras para a adoção de SAFs neste município, segundo a percepção dos agricultores locais (POMPEU et al., 2009).

Os lotes com SAFs comerciais apresentaram grande amplitude em termos de tamanho (Tabela 4). Devido à presença de valores extremos, verificase que a moda é menor do que a média e igual à mediana. Portanto, pode-se inferir que o tamanho médio do lote é 25 ha, o mesmo da mediana, ao invés de 34 hectares.

A frequência dos lotes com tamanho inferior a 25 ha foi $24,5 \%$. Mais da metade dos lotes pesquisados $(52,8 \%)$ apresentou área de 25 a 49 hectares, enquanto os lotes com tamanho entre 50 e 74 hectares constituíram apenas $11,3 \%$ do total. A frequência dos lotes com tamanho entre 75-100 hectares foi de apenas 5,7\%, o mesmo acontecendo com os lotes com tamanho acima de 100 hectares.

Tabela 4. Medidas estatísticas referentes à área dos lotes e à área dos SAFs dos agricultores familiares no Município de Bragança, Pará. $\mathrm{n}=53$

\begin{tabular}{lcc}
\hline Medidas Estatísticas & $\begin{array}{l}\text { Área dos } \\
\text { lotes (ha) }\end{array}$ & $\begin{array}{l}\text { Área dos } \\
\text { SAFs (ha) }\end{array}$ \\
\hline Média & 34 & 2 \\
Mediana & 25 & 2 \\
Moda & 25 & 2 \\
Desvio padrão & 29,7 & 1,25 \\
Mínimo & 2 & 0,1 \\
Máximo & 150 & 5 \\
\hline
\end{tabular}

Os dados ora apresentados refletem o processo de minifundiarização existente no município de Bragança, decorrente da fragmentação da estrutura fundiária, ocasionada, sobretudo, pelo crescimento demográfico. Vale ressaltar que o Município de Bragança é uma velha fronteira agrícola, cujo início do processo de ocupação data do século XVII (CONCEIÇÃO, 1990). O processo de minifundiarização nos municípios da microrregião bragantina também foi relatado por Vieira et al. (2007) e Rosa et al. (2009).

Guimarães Filho, Saltier e Sabourim (1998), ao analisarem a minifundiarização na Amazônia, afirmam que o baixo nível tecnológico predominante na agricultura familiar gera renda insuficiente às famílias de agricultores, dificultando sua condição de produtividade e, por conseguinte, contribui diretamente com esse processo.

As áreas destinadas aos SAFs variaram de 0,1 ha a 5 ha . A maioria dos 53 agricultores destinou cerca de 2 ha da área dos lotes para a implantação dos SAFs. Aproximadamente $21 \%$ dos SAFs apre- 
sentaram área inferior a 1 ha. O percentual restante (79\%) apresentou área de 1 até 5 ha.

Ao se investigar a relação entre o tamanho do lote e o tamanho do SAF, constatou-se que não houve correlação $(\mathrm{r}=0,10)$ entre o tamanho do lote e a área utilizada com SAFs. Portanto, é possível inferir que o tamanho do lote não é um fator limitante à adoção de SAFs comerciais pelos agricultores familiares de Bragança.

O baixo grau de associação entre o tamanho do lote e o da área utilizada com SAFs foi observado em Igarapé-Açu (VIEIRA et al., 2007), na microrregião Bragantina, no Estado do Pará.

A pequena área destinada aos SAFs pode ser explicada pelo tamanho do lote, cujo módulo fiscal, no município, é de 25 ha, assim como pelo conhecimento parcial dos agricultores sobre a implantação, manejo e benefícios destes sistemas; pela falta de financiamentos governamentais e, finalmente, por questões econômicas relacionadas à insegurança com relação aos riscos na comercialização dos produtos gerados nos SAFs.

Além dos SAFs, foram identificados sete outros sistemas de uso da terra empregados pelos agricultores familiares em Bragança. Os sistemas mais praticados pelos agricultores familiares foram a criação de pequenos animais (patos, galinhas, porcos, entre outros) e os cultivos anuais (arroz, feijão, mandioca e milho), 66,04 e 47,2\%, respectivamente. A criação de pequenos animais ocorre nos quintais agroflorestais, e está presente em todos os lotes das famílias de agricultores de Bragança. A mulher é a principal responsável por esta atividade. O papel marcante da mulher no estabelecimento e manejo dos quintais agroflorestais, em Bragança, também foi constatado por Rosa et al. (2007), e em outros municípios do Nordeste paraense (ROSA, 2002; VIEIRA et al., 2008; 2009).

Florestas secundárias são mantidas por 45,3\% dos agricultores, enquanto somente $26,4 \%$ conservam fragmentos de floresta primária. A ocorrência de florestas secundárias está diretamente ligada ao período de pousio do solo. Anteriormente, o período de pousio era de 10 anos, entretanto, devido ao processo de expansão da fronteira agrícola, este período foi reduzido para 5 anos (HOHNWALD et al., 2003), comprometendo a fertilidade do solo e a sustentabilidade da produção.

A pecuária incentivada por programas governamentais é praticada por $21 \%$ dos agricultores, sobretudo pelos que possuíam lotes maiores. Em contrapartida, os sistemas de uso da terra menos identificados nas áreas dos agricultores foram os cultivos perenes $(7,5 \%)$ e a floresta plantada $(1,9 \%)$, denotando a falta de políticas públicas eficazes que incentivem o reflorestamento na agricultura familiar. D`Incao (2000), ao estudar os sistemas de uso da terra praticados no Estado de Tocantins, verificou que a pecuária foi o sistema menos praticado pelos agricultores familiares deste estado. Segundo esta autora, em média, 6 ha estavam recobertos por florestas secundárias, 6 ha eram destinados às roças para o cultivo de espécies anuais e 3,5 ha para pecuária.

A diversificação dos sistemas de uso da terra em Bragança deve-se, em parte, aos programas governamentais, que proporcionaram financiamento aos agricultores familiares, e a questões socioculturais, como tradições familiares, inclusive relacionadas aos hábitos alimentares.

Rosa et al. (2009) relatam que $41,7 \%$ dos 410 SAFs identificados na microrregião Bragantina foram financiados pelo Fundo Constitucional do Norte (FNO-Especial) e que $44,1 \%$ resultaram da iniciativa dos próprios agricultores.

É importante destacar que os financiamentos oriundos dos programas governamentais em Bragança foram, principalmente, destinados aos monocultivos de espécies agrícolas (anuais e perenes) de valor comercial. No entanto, em muitos casos, os agricultores locais por iniciativa própria diversificaram estes cultivos, transformando-os em SAFs. O fenômeno de diversificação dos SAFs também foi observado no município de Igarapé Açu (VIEIRA et al., 2007) e em outros municípios da microrregião Bragantina (ROSA et al., 2009).

Em Bragança, os SAFs fornecem multiprodutos destinados principalmente à comercialização (grãos de feijão, arroz, milho; raízes de mandioca; sementes de pimenta-do-reino; frutos de abacaxi, laranja, coco, açaí, caju, manga, pupunha e cupuaçu). Outros produtos (frutos de abacate, urucum, ingá cipó etc.) são utilizados tanto para a comercialização como para a autoconsumação, denotando a influência da tradição agrícola e a importância dos SAFs para a segurança alimentar dos agricultores locais.

A comercialização de frutos e de grãos oriundos de SAFs também foi constatada em outros municípios da microrregião Bragantina (VIEIRA et al., 2007; ROSA et al., 2009), o que denota a importância destes produtos para a economia familiar, nesta microrregião.

No tocante à renda bruta familiar mensal familiar, foi constatado que $22,6 \%$ dos agricultores 
alcançaram renda superior a $\mathrm{R} \$ 600,00$ (seiscentos reais), 41,5\% obtiveram renda entre $\mathrm{R} \$ 300,00$ e R\$ 600,00 (trezentos e seiscentos reais), 35,8\% apresentaram renda inferior a $\mathrm{R} \$ 300,00$ (trezentos reais).

Com relação à renda familiar mensal gerada pelos SAFs, verificou-se que 21,3\% dos agricultores obtiveram renda de até $\mathrm{R} \$ 50,00$ (cinquenta reais), $21,3 \%$ geraram renda entre $\mathrm{R} \$ 50,00$ e $\mathrm{R} \$ 300,00$ (cinquenta e trezentos reais) e 19,3\% obtiveram renda superior a $\mathrm{R} \$ 300,00$ (trezentos reais).

Em contrapartida, $35,2 \%$ dos agricultores não obtiveram ou não souberam informar a renda gerada, visto que, na época da pesquisa, muitos SAFs não se encontravam na fase produtiva, por serem recém implantados.

A análise estatística descritiva da renda mensal realizada com 36 agricultores (pois 17 agricultores não obtiveram renda com os SAFs, pelos motivos acima expostos), mostrou que a renda média foi baixa ( $R \$ 136,38)$, devido à grande amplitude decorrente dos valores máximos e mínimos de renda (Tabela 5).

De acordo com Rosa et al. (2009), a baixa renda obtida nos SAFs na microrregião Bragantina deve-se a três aspectos: dificuldade no escoamento e comercialização dos produtos gerados pelos SAFs; custos referentes à implantação, manutenção e colheita dos SAFs e SAFs que não se encontravam na fase produtiva, por serem recém-implantados.

Segundo os agricultores locais, os produtos dos SAFs que mais contribuíram para a geração de renda foram: pimenta-do-reino, feijão e mandioca, esta última através da comercialização da produção de farinha. Nas palavras dos agricultores locais, "são estas as espécies que pagam as contas da casa".

Tabela 5. Medidas estatísticas referentes à renda mensal obtida com os sistemas agroflorestais pelos agricultores familiares do Município de Bragança, Pará $(n=36)$.

\begin{tabular}{lc}
\hline Medidas Estatísticas & Renda dos SAFs (R\$) \\
\hline Média & 136,38 \\
Mediana & 143,75 \\
Moda & 60,00 \\
Desvio padrão & 189,00 \\
Mínimo & 36,33 \\
Máximo & 749,00 \\
\hline
\end{tabular}

Os resultados do estudo em Bragança demonstraram que, embora a renda gerada pelos SAFs, em Bragança, não seja tão alta, ela contribui com o orçamento das famílias dos agricultores.
Além da função produtora, os agricultores reconheceram a função protetora dos SAFs, destacando a importância das essências florestais presentes nestes sistemas (Acacia mangium Willd, Carapa guianensis Aubl., Tabebuia sp., Ceiba pentandra (L.) Gaertn., Simarouba amara Aublet., Cedrela odorata L., Cordia goeldiana Huber e Switenia macrofila King., entre outras), em relação ao sombreamento, ao aumento da fertilidade do solo e para a recuperação das áreas alteradas, entre outros benefícios ambientais.

\section{Conclusões e Recomendações}

As características socioeconômicas e a procedência dos agricultores influenciaram a adoção de sistemas agroflorestais comerciais, em Bragança.

A mão de obra familiar representa a maior expressão nos trabalhos desenvolvidos nos SAFs, sendo que o homem é o principal responsável pela adoção dos sistemas.

Os SAFs, em geral, são importantes para a economia dos agricultores familiares. Contudo, políticas públicas são necessárias para que estes sistemas se tornem sustentáveis, do ponto de vista socioeconômico: ampliação das áreas dos SAFs comerciais; garantia de assistência técnica; adequação dos produtos gerados ao mercado consumidor, para aumentar a renda e esclarecer os produtores rurais sobre os projetos de financiamentos.

\section{Agradecimentos}

Ao World Agroforestry Centre (Icraf), pelo apoio financeiro, em especial a Jan Beniest. Aos agricultores familiares e aos representantes das organizações comunitárias de Bragança, pela disponibilidade e valiosa contribuição ao desenvolvimento do estudo.

\section{Referências}

BRUMER, A. Gênero e agricultura: a situação da mulher na agricultura do Rio Grande do Sul. Estudos Feministas, Florianópolis, v.12, n.1, p.205227, 2004.

CHAMBERS, R. Shortcut methods in social information gathering for rural development projects. International Conference on Rapid Rural Appraisal. Khon Kaen: Khon Kaen University Press, 1987. 13p. 
CONCEIÇÃO, M.F.C. Políticas e colonos na Bragantina, Estado do Pará: Um trem, a terra e a mandioca. 1990, 320f. Dissertação (Mestrado em Sociologia) - Universidade Estadual de Campinas, Campinas, 1990.

D'INCAO, M.C. A construção de uma estratégia de desenvolvimento sustentável para a agricultura familiar na Amazônia: O projeto agroflorestal no centro agroambiental do Tocantins. In: HÉBETTE, J.; NAVEGANTES, R. da S. (Orgs.). CAT-Ano décimo: etnografia de uma utopia. Belém: UFPA, CAT, 2000. p.200.

DUBOIS, J.C.L.; VIANA, V.M.; ANDERSON, A.B. Manual agroflorestal para a Amazônia. Rio de Janeiro: Rebraf, 1996. v.1, 228p.

ESTATÍSTICAS MUNICIPAIS: BRAGANÇA. Disponível em: <http://www.sepof.pa.gov.br/Bragança. cfm> Acesso em: 20 nov. 2007.

FRANKE, I.L.; LUNZ, A.M.P.; AMARAL, E.F. Caracterização sócio-econômica dos agricultores do grupo Nova União, Senador Guiomard Santos, Acre: ênfase para implantação de sistemas agroflorestais. Rio Branco: Embrapa-CPAF/AC, 1998. (EmbrapaCPAF/AC. Documentos, 33). 39p.

FRANZEL, S.; SCHERR, S.J.; COE, R.; PHIRI, D.; KWESIGA, F. Methods for accessing agroforestry adoptions potential. In: FRANZEL, S.; SCHERR, S.J. (Eds.). Trees on the farm: assessing the adoption potential of agroforestry practices in Africa. Nairobi: CAB International: Icraf, 2002. p.11-35.

GUIMARÃES FILHO, C.; SALTIER, D.; SABOURIM, E. Pesquisa e desenvolvimento: subsídios para o desenvolvimento da agricultura brasileira. Brasília: Embrapa - SPI/ Petrolina: Embrapa-CPASA, 1998. 123p.

HOHNWALD, S.; RISCHKOWSKY, B.; CAMARÃO, A.P.; RODRIGUES FILHO, J.A. Pastagem com regeneração da capoeira ou pastagem consorciada com leguminosas: possibilidades de integração da pastagem no ciclo agrícola tradicional na zona Bragantina, Pará, Brasil. In: FICHTL, A.; TOURRAND, J-F. (Eds.). Viabilidade de sistemas agropecuários na agricultura familiar na Amazônia. Belém: Embrapa Amazônia Oriental, 2003. p.136.

LUDOVINO, R.M.R. Análise da diversidade e da dinâmica da agricultura familiar na Amazônia Oriental: o caso da zona Bragantina. 2002. 370f. Tese (Doutorado em Agronomia)-Universidade Técnica de Lisboa, Instituto Superior de Agronomia, Lisboa, 2002.

MAIA, C.; CELESTINO FILHO, P.; SALGADO, I. Experiências de agricultores familiares da Transamazônica, Estado do Pará. In: SIMÕES, A. (Org.). Coleta amazônica - Iniciativas em pesquisa, formação e apoio ao desenvolvimento rural sustentável na Amazônia. Belém: Alves, 2003. p.215-218.

PEREIRA, C.L. de O. Viabilidade de sistemas agroflorestais dos agricultores familiares do Município de Santo Antonio do Tauá, Pará. Agricultura Familiar: Pesquisa, Formação e Desenvolvimento, Belém, v.4, n.4, p.113-118, 2004.

POMPEU, G.S.S.; ROSA, L.S.; MODESTO, R.S.; SANTOS, M.M.; RODRIGUES, A.F. Sistemas agroflorestais comerciais em áreas de agricultores familiares no município de Bragança, Pará: um estudo de caso. Revista de Ciências Agrárias, n.51, p.191210, 2009.

ROSA, L.S. Limites e possibilidades do uso sustentável dos produtos madeireiros e não madeireiros na Amazônia brasileira: o caso dos pequenos agricultores da Vila Boa Esperança, em Moju, no Estado do Pará. 2002, 304f. Tese (Doutorado em Desenvolvimento Sustentável do Trópico Úmido) Universidade Federal do Pará/ Naea, Belém, 2002.

ROSA, L.S.; SILVEIRA, E.L.; SANTOS, M.M.; MODESTO, R.S.; PEROTE, J.R.S.; VIEIRA, T.A. Os quintais agroflorestais em áreas de agricultores familiares no município de Bragança-PA: composição florística, espécies e divisão de trabalho familiar. Revista Brasileira de Agroecologia, v.2, n.2, p.337341, 2007.

ROSA, L.S.; VIEIRA, T.A.; SANTOS, A.P.A.; MENESES, A.A.S.; RODRIGUES, A.F.; PEROTE, J.R.S.; LOPEZ, C.V.C. Limites e oportunidades para a adoção de sistemas agroflorestais pelos agricultores familiares da microrregião Bragantina, PA. In: PORRO, R. (Org.). Alternativa agroflorestal na Amazônia em transformação. Brasília: Embrapa/ Icraf, 2009. p.645-670.

SILIPRANDI, E. Ecofeminismo: contribuições e limites para a abordagem de políticas ambientais. Agroecologia e Desenvolvimento Rural Sustentável, v.1, n.1, p.61-71, 2000.

VIEIRA, A.T.; ROSA, L.S; VASCONCELOS, P.S.S.; SANTOS, M.M.; MODESTO, R.S. Adoção de sistemas agroflorestais na agricultura familiar em Igara- 
pé-Açú, Pará, Brasil. Revista de Ciências Agrárias, n.47, p.9-22, 2007.

VIEIRA, T.A.; ROSA, L.S.; MODESTO, R.S.; SANTOS, M.M. Gênero e sistemas agroflorestais: o caso de Igarapé-Açu, Pará, Brasil. Revista de Ciências Agrárias, n.50, p.143-154, 2008.
VIEIRA, A.T.; ROSA, L.S.; MODESTO, R.S.; SANTOS, M.M.; SANTOS, E.R.A.; ARAÚJO, A.B.B.; ARAÚJO, S.L.F. Relações de gênero em sistemas agroflorestais: o caso da microrregião Bragantina, PA. In: PORRO, R (Org.). Alternativa agroflorestal na Amazônia em transformação. Brasília: Embrapa Informação Tecnológica, 2009. p.645-670. 